\title{
WATER QUALITY MODELING USING ARTIFICIAL INTELLIGENCE-BASED TOOLS
}

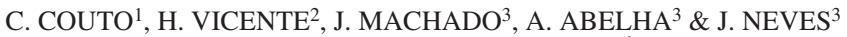 \\ ${ }^{1}$ Department of Chemistry, University of Évora, \\ Portugal (e-mail: horbite@gmail.com). \\ ${ }^{2}$ Department of Chemistry and Chemistry Centre of Évora, University of Évora, \\ Portugal (e-mail: hvicente@uevora.pt). \\ ${ }^{3}$ Department of Informatics, University of Minho, Braga, \\ Portugal (e-mail: \{jmac, abelha, jneves\}@di.uminho.pt).
}

\begin{abstract}
Water, like any other biosphere natural resource, is scarce, and its judicious use includes its quality safeguarding. Indeed, there is a wide concern to the fact that an inefficient water management system may become one of the major drawbacks for a human-centered sustainable development process. The assessment of reservoir water quality is constrained due to geographic considerations, the number of parameters to be considered and the huge financial resources needed to get such data. Under these circumstances, the modeling of water quality in reservoirs is essential in the resolution of environmental problems and has lately been asserting itself as a relevant tool for a sustainable and harmonious progress of the populations. The analysis and development of forecast models, based on Artificial Intelligence-based tools and the new methodologies for problem solving, has proven to be an alternative, having in mind a pro-active behavior that may contribute decisively to diagnose, preserve, and rehabilitate the reservoirs. In particular, this work describes the training, validation and application of Artificial Neural Networks (ANNs) and Decision Trees (DTs) to forecast the water quality of the Odivelas reservoir, in Portugal, over a period of 10 years. The input variables of the ANN model are chemical oxygen demand (COD), dissolved oxygen (DO), and oxidability and total suspended solids (TSS), while for the DT the inputs are, in addition to those used by ANN, the Water Conductivity and the Temperature. The performance of the models, evaluated in terms of the coincidence matrix, created by matching the predicted and actual values, are very similar for both models; the percentage of adjustments relative to the number of presented cases is $98.8 \%$ for the training set and $97.4 \%$ for the testing one.
\end{abstract}

Keywords: Artificial Neuronal Networks, data mining, Decision Trees, water quality.

(C) 2012 WIT Press, www.witpress.com

ISSN: 1755-7437 (paper format), ISSN: 1755-7445 (online), http://journals.witpress.com

DOI: 10.2495/DNE-V7-N3-299-308 